\title{
Penile Infection, CTCAE
}

National Cancer Institute

\section{Source}

National Cancer Institute. Penile Infection, CTCAE. NCI Thesaurus. Code C143741.

A disorder characterized by an infectious process involving the penis. 